\title{
VERDAD Y PERFORMATIVIDAD: \\ LA PERSONIFICACIÓN AMBIGUA EN FERnANDo VALLEJO*
}

\author{
Truth and Performativity: The \\ Ambiguous Personification in Fernando \\ VALLEJo
}

Xavier Villacreses Benavides ${ }^{1}$

\begin{abstract}
* Articulo derivado de la investigación doctoral "Extrapolaciones: ética literaria y discurso crítico en Roberto Bolaño, Ricardo Piglia y Fernando Vallejo" desarrollada en la University of British Columbia, Vancouver, Canadá.
\end{abstract}

Cómo citar este artículo: Villacreses Benavides, X. (2021). Verdad y performatividad: la personificación ambigua en Fernando Vallejo. Estudios de Literatura Colombiana 48, pp. 153-169. DOI: https:// doi.org/10.17533/udea.elc.n48a10

1 https://orcid.org/0000-0002-7513-8333 xavier.villacresesb@gmail.com University of British Columbia, Canada

Editores: Andrés Vergara Aguirre, Christian Benavides Martínez, Valentina Noreña Gómez

Recibido: 31.07 .2020

Aprobado: 31.10 .2020

Publicado: 18.12.2020

Copyright: (2021 Estudios de Literatura Colombiana. Este es un artículo de acceso abierto distribuido bajo los términos de la Licencia Creative Commons Atribución No comercial - Compartir igual 4.0 Internacional
Resumen: Este artículo analiza la relación que existe entre el proyecto autorreferencial de Fernando Vallejo y la representación de su persona pública. A través del análisis de su narrativa y su discurso crítico se plantea que su proyecto presenta dos rasgos que no han sido estudiados: una narrativa autobiográfica sostenida sobre un narrador-personaje poco fiable y la identificación ambigua con este personaje en sus apariciones y registros públicos. Se sugiere que esta estrategia creativa opera como una crítica de los efectos de verdad que produce el escritor sobre su recepción en los medios de comunicación.

Palabras clave: Fernando Vallejo; público; performance; discurso; representación.

Abstract: This article analyzes the relationship that exists between Fernando Vallejo's self-referential project and the representation of his public persona. Through the analysis of his narrative and critical discourse, it argues that his project presents two features that have not been studied: an autobiographical narrative sustained on an unreliable narrator-character and the ambiguous identification with this character in his appearances and public records. It is suggested that this creative strategy operates as a critique of the effects of truth that the writer produces on his reception in the media.

Keywords: Fernando Vallejo; public; performance; discourse; representation. 


\section{El escritor y el público}

La literatura de Fernando Vallejo permite a los lectores estudiar de forma ejemplar cómo dentro del proyecto creativo de un escritor pueden interactuar funciones críticas y performativas. El corpus primordial de este trabajo está enmarcado en el discurso crítico de Vallejo recogido en el libro Peroratas (2015) y en el material narrativo de la pentalogía de novelas del ciclo El río del tiempo (1999); ${ }^{1}$ el objetivo es señalar la operación de la personificación en el escritor y cómo trabaja desde el espacio público sobre niveles ficcionales y no ficcionales a la vez para producir un efecto de incertidumbre en la audiencia; para esto se explora en este ensayo la construcción del personaje de Fernando Vallejo, su relación con el concepto de verdad y el sentido de sus estrategias públicas de presentación.

Entiendo al discurso crítico como una función valorativa cuyo propósito es la construcción y divulgación de ideas sobre la literatura o relacionadas con esta de forma directa o indirecta que permitan establecer un juicio sobre ella o sobre la figura del escritor, la cual aparece sobre todo en artículos, discursos o entrevistas. Por su parte, entiendo como personificación a las acciones performativas que realiza un escritor para representar su papel como tal ante una audiencia con cierta regularidad y que permite influir de alguna manera sobre esta al comunicar por medio de ellas su posición social. ${ }^{2}$ En este caso hago referencia a la capacidad consciente o no del escritor para jugar con su figura y su historia biográfica, y producir así una narrativa pública sobre su vida capaz de ser consumida en relación con su lugar en el campo literario.

$\mathrm{El}$ origen de estas funciones puede identificarse a partir de la segunda mitad del siglo XIX, un periodo de radical importancia en la historia del escritor moderno. En este momento, además de consolidarse una lógica antieconómica que buscó determinar el valor a partir de criterios que excluyeran lo extraliterario (Bourdieu, 1995, p. 214), se dieron cambios en la relación del escritor ante el público. Entre estos, la importancia cada vez mayor de los medios escritos como forma primordial de construir el valor literario sobre la discusión pública (Habermas, 1997, p. 193) y la percepción social

$1 \quad$ El río del tiempo (1999), recoge en un solo volumen las novelas Los días azules (1985), El fuego secreto (1987), Los caminos a Roma (1988), Años de indulgencia (1989) y Entre fantasmas (1993), dado que estas pertenecen a un mismo ciclo narrativo autobiográfico del autor. En este trabajo todas las citas a estas novelas provienen del volumen El río del tiempo de 1999.

2 El uso del término "performativo" en este trabajo se corresponde con el concepto de performance, elaborado por Erwin Goffman (2001) que comprende "la actividad total de un participante dado en una ocasión dada que sirve para influir de algún modo sobre los otros participantes” (p. 27). 
del artista como agente expresivo en los términos modernos de personalidad y autenticidad (Sennett, 1978, p. 329) son determinantes para entender el desarrollo de una conciencia cada vez mayor del escritor en el espacio público y el correspondiente interés general sobre su biografía y sus opiniones.

El interés sobre la figura pública del escritor no puede considerarse como un fenómeno absolutamente moderno. Los escritos biográficos sobre Dante Alighieri, Francesco Petrarca o Giovanni Boccacio producidos desde la Baja Edad Media constituyen referentes para entender la dimensión pública del escritor y la valoración de la individualidad del artista que tiene lugar en el Renacimiento. La figura de Dante es cardinal en esto, ya que él construye una figura heroica del poeta, en la que lo autobiográfico, lo histórico y lo ficcional se encuentran vinculados, y prefiguran con esto la construcción épica del escritor moderno (Barolsky, 2010, pp. 48-49).

Esta relación de lo histórico y lo mítico en la figuración pública del escritor se cristaliza de forma definitiva con el Romanticismo. El uso de la categoría de "genio" en el siglo XVIII señala con claridad este momento, ya que un término de origen y connotaciones religiosas se convierte en una categoría de análisis artístico por medio del desarrollo de la estética. El genio en la estética kantiana funciona como una naturalización de la concepción mítica del creador, quien es deshistorizado y separado epistemológicamente de su creación. En su Crítica del juicio Kant afirma que el genio ignora de dónde provienen sus ideas y es incapaz de comunicarlas, por lo que su lugar está limitado a la creación original de modelos equivalentes a la naturaleza (citado en Soussloff, 1997, p. 7). Al posicionar al creador en un plano metafísico vinculado con nociones como lo universal, lo absoluto o lo verdadero, la estética produce una escisión entre el creador y el objeto artístico. A fines del siglo XIX, como indica Raymond Williams, esta ruptura entre ambos llega a tal punto que el uso del término genio por parte del público deja de estar relacionado con la habilidad o práctica creativa, y pasa más bien a denotar características de temperamento y sensibilidad en el creador (citado en Sennett, 1978, p. 248).

La sociedad decimonónica produce lo que podemos considerar como las dos características modernas de la construcción cultural del escritor: la naturalización de su práctica que produce un interés creciente sobre su personalidad, y el desarrollo de un sistema mediático que permite la exposición de esta personalidad al público. No es casual que, en la última década del siglo xıx, tanto en Francia como en Estados 
Unidos aparezcan las primeras entrevistas literarias, ya que estas son el reflejo de esta nueva dinámica entre el escritor y la audiencia que hace de la personalidad del autor un objeto de interés general. Esta exposición pública lleva a que lo público y privado en la figura del escritor se confundan. Para el nuevo público no solo basta con que el escritor produzca una obra; también es necesario que el autor y la obra sean reconocidas por el público en un sentido amplio (Habermas, 1997, p. 202).

Existen dos hechos de largo alcance en el sistema literario producidos por esta transformación histórica sobre el escritor: el primero, cuyo estudio minucioso escapa a la intención de este trabajo, consiste en la progresiva desaparición del autor como objeto de investigación conforme la literatura se institucionaliza como disciplina académica en el siglo xx, y tiene su punto más álgido en el paradigma posestructuralista francés y su interés en las relaciones entre el texto y la audiencia, lo que presupone un lector ideal limitado al consumo e interpretación textual; el segundo, sobre el que me extenderé en este trabajo, sucede sobre el escritor, cuyo territorio de producción se amplía hacia una función crítica y otra performativa como resultado de su nueva situación pública. He denominado al inicio de este trabajo a estas funciones como discurso crítico y personificación; en adelante indicaré cómo estas funciones nos permiten explicar el universo creativo de Fernando Vallejo.

\section{La construcción del personaje}

En Vallejo coinciden tres elementos representativos de la literatura latinoamericana de finales del siglo xx e inicios del xxı: el uso de elementos autobiográficos en su proyecto narrativo, la exposición de un discurso crítico que funciona como crítica de la nación y una personificación próxima a su representación autoral en su narrativa autobiográfica. En el caso de Vallejo, propongo en este trabajo que esta personificación tiene como característica particular la ambigüedad, ya que funciona al mismo tiempo como una personificación del autor y del personaje, lo que produce un efecto de indeterminación sobre sí mismo ante el público, el cual es coincidente tanto con sus postulaciones filosóficas y literarias como con el contexto político colombiano.

Podemos afirmar que Vallejo construye su proyecto literario sobre una base que es en esencia ética y que toma la forma de mitología de artista tanto en su producción narrativa como en su personificación. El mito del origen creativo que Vallejo elabora en su discurso crítico y en el conjunto de novelas que forman El río del tiempo pro- 
pone una historia en la que el impulso creativo pasa de la música al cine y de allí a la literatura. Se puede identificar el aspecto ético en su representación autoral puesto que la creación cinematográfica se relaciona con la reconstrucción y la exposición de la violencia política. Sobre esto escribe en Los caminos a Roma (1988):

En el lapso de un relámpago la vi completa, un instante de iluminación que abarcaba la hora y media que duraría y el siglo y medio que representa. Vi a Colombia: el genocidio del Dovio, el genocidio del Fresno, el genocidio del Líbano, el genocidio del Águila, el genocidio de Tuluá, el genocidio de Supía, el genocidio de Riosucio, el genocidio de Cajamarca, el genocidio de Sevilla, el genocidio de Anserma, el genocidio de Génova, el genocidio de Icononzo, el genocidio de Salento, el genocidio de Armero, el genocidio de Irra, el genocidio de Falan... Vi los decapitados. Decenas, centenas de cuerpos sin cabeza, descalzos, camisas de manga corta y pantalones de dril. Y las cabezas acomodadas a la buena de Dios, como un piadoso ejercicio, como un monstruoso acertijo, intento de adivinar cuál correspondía a quién (Vallejo, 1999, pp. 397-398).

La mención de estos hechos relativos a la Violencia aparecen de nuevo en su discurso crítico acompañados de una increpación: “¿Colombia ya los olvidó? ¿Es que con tanto muerto le entró el mal de la desmemoria y se le borró la historia? A mí no" (Vallejo, 2015, p. 44). Detrás de la representación social del artista como enemigo de la sociedad, que aparece aquí y tiene su fundamento en el siglo xix en Europa, subyace la idea de que la creación artística debe ser independiente de las valoraciones políticas y morales; por lo tanto, el artista puede establecer un juicio sobre los hechos sociales en sus creaciones que la sociedad retratada no podrá juzgar en términos morales, sino artísticos. Esta visión ideal se rompe en la representación autobiográfica de Vallejo cuando le son negados los permisos para filmar y exhibir en Colombia sus películas Crónica roja (1977) y En la tormenta (1980) por ser consideradas como "apología del delito”(p.230). La representación de este rechazo se asocia en la narración de Vallejo con la separación de Colombia, el abandono del cine y el ingreso en la literatura.

La escritura en la representación que elabora Vallejo va unida a la ruptura y la transgresión. Su posición es fundamentalmente ética en el sentido que establece que un problema hay que "desenmascararlo quemándolo" (Vallejo, 1999, p. 512); la práctica literaria deberá ser entendida entonces como una herramienta moral para deconstruir la nación, y la distancia de la sociedad colombiana como una situación necesaria para observarla verdaderamente. Ser parte de Colombia sin ser parte de ella: una relación ambivalente que en Vallejo es representada y experimentada en términos personales y que da lugar tanto a la creación del personaje Vallejo como al uso definitivo de la primera persona desde la publicación de Los días azules en 1985 en adelante. 
Lo expuesto puede identificarse como una fase madura del proyecto representacional que elabora Vallejo, ya que para funcionar ante la audiencia necesita la conjunción de sus novelas, su discurso crítico y su personificación; los dos últimos adquirirán importancia creativa a partir del interés público que se produce tras la publicación de La virgen de los sicarios en 1994 y la producción y realización de la película del mismo nombre por Barbet Schroeder en 1999. Si bien este es el momento histórico a partir del cual presentaré la forma cómo interactúan sus novelas, su discurso crítico y su personificación, es necesario antes remitirnos a la escritura de Barba Jacob, el mensajero de 1984 y a El río del tiempo, ya que a partir de ambos lugares se construyen las bases de la representación creativa que caracterizan a Vallejo.

Se puede decir que en la primera versión de la biografía que Vallejo escribe sobre Porfirio Barba Jacob identifica y asimila dos elementos de importancia para su proyecto creativo: el primero es el valor de la irreverencia y la provocación como rasgos éticos del escritor construidos a partir de la oposición simbólica entre el escritor y la sociedad. Como indica Julia Musitano (2017), en Barba Jacob, Vallejo descubre el valor literario de la construcción de la leyenda personal: "Colombiano devenido mexicano, periodista mercenario, defensor de ideas liberales, homosexual, sifilítico, marihuanero, alcohólico, maldito engominado de espíritu conservador, poeta y oportunista, contradictorio hasta la médula; todo eso era Porfirio Barba Jacob” (p. 146). El segundo elemento que Vallejo asimila es el uso creativo de la ficción del nombre. De acuerdo con ello cabe preguntar ¿cuál es el límite de la presentación del Yo ante los demás?, ¿mantiene el Yo una unidad histórica?, ¿es confiable su narración? Barba Jacob se aproxima a estas cuestiones con una irreverencia suprema que Vallejo presenta como el proceso camaleónico del hombre que se suicidó tres veces:

Contó cómo dio muerte a Miguel Ángel Osorio y su reciente homicidio de Ricardo Arenales: Había llegado a un país desconocido, sin un centavo, con el solo traje que llevaba puesto por todo equipaje: "Ya que no llevaba nada conmigo, nada en absoluto, quise despojarme de lo único que me acompañaba, mi nombre. Y una vez más el acero de mi propia voluntad asesinó mi propio yo". Le preguntaron cómo había personalizado su nuevo yo y repuso: "Lo formé como se forma al protagonista de una novela. Lo dediqué a nuevas actividades y hasta concebí para él nuevos vicios. Lo único que no pude dejar de ser fue poeta" (Vallejo, 1984, p. 229).

El valor creativo de la inestabilidad de la personalidad es una lección fundamental aquí; la identidad pública es entendida como una ficción, capaz de elaborarse y modi- 
ficarse a voluntad, porque el nombre propio y la historia que lleva consigo no es más que una máscara, una ilusión:

[...] entendí un día, de improviso, como una revelación, que por sobre la aparente extravagancia su empeño en cambiarse de nombre ocultaba una profunda realidad: él había intuido la falacia del lenguaje que es designar en igual forma al niño, al joven, al hombre y al anciano, y que en el correr de la vida el nombre sólo da una ilusoria continuidad (p. 499).

Junto a la defensa del lenguaje literario expuesta en Logoi (1983) que permite comprender la estructura formal y lingüística de la escritura en Vallejo, tanto el valor simbólico de la irreverencia pública en el escritor como la ficción del nombre son fundamentales para entender la elaboración del personaje autobiográfico en El río del tiempo. Allí se pueden identificar dos líneas generales relacionadas con este proceso: una representacional, que incluye la inestabilidad mental del personaje, la transgresión social, el uso del nombre propio del autor y la indeterminación entre elementos biográficos y ficcionales que dan forma a la narración; junto a esta se encuentra una línea ética-crítica, presente en la desconfianza del personaje hacia el humanismo y el antropocentrismo, en la crítica de la nación, en especial de sus instituciones políticas y religiosas, y en el desarrollo de un discurso crítico literario que asocia el uso absoluto de la primera persona en la literatura con el concepto de verdad y que pregona la decadencia contemporánea de la producción literaria.

Es necesario resaltar la inestabilidad mental del personaje en El rio del tiempo, la cual es identificada como un mal familiar caracterizado por la terquedad y que está representado por el estridente golpe de cabeza del personaje contra el piso que abre y cierra este ciclo de novelas. Esta inestabilidad es clave para entender una serie de actos que se distancian de la representación biográfica y que entran en la ficción, como son el incendio de la estatua de Bolívar en Medellín (Vallejo, 1999, p. 324), el asesinato de una conserje en Francia (p. 367), el de un turista gringo en España (p. 377) o el incesto homosexual con su hermano en Nueva York (p. 468). Hacia el final de El fuego secreto este comportamiento lleva a que el personaje sea internado en una clínica psiquiátrica donde se le administra una inyección de insulina (p. 320), tratamiento con el cual se solía tratar la esquizofrenia hasta mediados del siglo xx. Luego de esto escapa para volver junto a su madre: 
¡Ay niña, qué ingenua has podido ser con tantos hijos! ¿No ves el crimen que es perpetuar la vida, el dolor, el horror? Me hizo entrar y con suavidad me llevó al comedor y me sirvió un chocolate. En ese instante sonó el teléfono. Contestó, algo dijo y luego, tapando la bocina para que no la oyeran me informó: -Es de la clínica. Que te escapaste. Que si no volvés vas a acabar de suicida o asesino, que es peor. ¿Qué les digo? No contesté. Destapó la bocina y les comunicó: —Resolví que el muchacho no regresa. Se queda aquí. Mándenle a mi marido la cuenta, muchas gracias y adiós (p. 323).

A partir de la inestabilidad mental del personaje, su narración queda en entredicho, lo que aumenta el grado de indeterminación sobre el relato y deja en suspenso la identificación entre autor y narrador. Esta construcción de Vallejo, en la que el nombre propio del autor coincide con un narrador no fiable, elude las clasificaciones teóricas del pacto que han sido propuestas para estudiar la autobiografía y la autoficción. Para Philippe Lejeune (1994), en el plano del análisis interno del texto no hay ninguna diferencia entre la autobiografía y la novela autobiográfica (p. 136), por lo que el pacto de lectura se establece por epitextos y paratextos (p. 153). Esta solución pragmática de lectura, como veremos a continuación, es desmontada por la personificación ambigua de Vallejo. Una perspectiva deconstruccionista, por otro lado, ignora las funciones públicas que operan en niveles extratextuales, por lo que resulta limitada para entender este caso. Por último, las diversas posiciones sobre la autoficción a partir de la identidad entre autor y narrador dejan que la operación autoficcional suceda en el horizonte de la recepción textual, a medio camino entre el pacto ficcional y el autobiográfico.

El proyecto creativo de Vallejo supera una teorización convencional, ya que la identidad entre autor y narrador es problemática en términos de credibilidad interna, como hemos visto, y por medio de su personificación ambigua, de forma extratextual, Vallejo se identifica públicamente con el narrador no fiable de sus textos (personificación del personaje), al mismo tiempo que toma distancia de él al considerarlo un personaje ficticio cuando asume su lugar como creador (personificación del autor). Esto produce un efecto de indeterminación sobre la audiencia puesto que de forma deliberada Vallejo construye una recepción contradictoria. Si aceptamos solo la personificación del personaje, asumimos que Vallejo, el escritor, raya con la locura; por otro lado, la existencia de la personificación del autor apunta hacia un elaborado proyecto performativo por parte del escritor, que en última instancia cuestiona su lugar y autoridad para establecer relatos de verdad, incluso si se trata de hechos biográficos. El pacto de lectura que Vallejo propone en este caso es el del lector como un subjetivista radical. 


\section{Verdad}

En una conversación con Francisco Villena, Vallejo se presenta a partir de su personificación del autor y relata la elaboración de su personaje en tercera persona tomando distancia de él. Allí sugiere que la locura y extravagancia del personaje son un medio para cuestionar a la sociedad: "lo que yo he ido sosteniendo en los libros míos ha sido, más a mi pesar, que el viejo piensa así, así y así, para burlarme de todo. Son libros terroristas porque, a fin de cuentas, como no tengo a nada que aferrarme tengo el derecho a burlarme de todo" (Villena Garrido, 2005, s. p.). Con esto puede observarse el interés ético detrás de la representación de Vallejo, ya que la crítica se produce sobre el sistema externo de creencias de la sociedad; el humor actúa como un poder desacralizador que rompe con la solemnidad del poder e invita al lector a reírse del entorno social.

Al señalar la veracidad biográfica del autor y verdad literaria como distintas, el interés desacralizador se extiende hacia el acto de lectura, y la existencia de una correspondencia entre ambas instancias se vuelve relativa:

[...] si yo crecí entre Sabaneta y Envigado carece de importancia. El narrador que hice en los libros míos es un loco para muchos. Decidí hacerlo excesivo, exagerado, contradictorio. Hice de él una subjetividad rabiosa, contraria a la objetividad del resto [...]. A pesar de su disidencia, mi narrador es sincero (Villena Garrido, 2005 , s. p.).

Esta sinceridad subjetiva y limitada del personaje no busca ser transmitida en la forma de una verdad histórica, ya que es verdadera en los términos y límites del propio personaje y del alcance de la práctica literaria. En su ensayo "La verdad y los géneros literarios", Vallejo (2015) se extiende al respecto: "Puesto que la novela, de primera o de tercera persona por igual, es invención, no cabe hablar de verdad en ella, y donde no cabe hablar de verdad tampoco cabe hablar de mentira [...] son dos espejismos que se anulan" (p. 163); con esto queda claro que para Vallejo la novela no puede ser el territorio de la verdad, y buscarla allí no puede ser más que un acto de ingenuidad por parte del lector; la valoración estética reemplaza la verosimilitud. Se propone una lectura que trascienda la convención de la creencia en el texto o en el autor y que parta desde un sentido ético crítico que ponga en duda la autoridad del relato: "Leer novelas es un acto de fe [...] lo que exige el lector —el lector ferviente, que cree en Dios- es que le cuenten todo, todo, sin importarle que le inventen” (p. 162). La construcción de un narrador subjetivo y contradictorio llama la atención sobre esto; para que se logre una ilusión de 
verdad biográfica en la narrativa de Vallejo, el lector tiene que leer sus novelas obviando las contradicciones internas y externas para creer en la identidad entre personaje y autor. La personificación del personaje en Vallejo añade otro nivel de complejidad a esto. Ya que en la mayoría de sus presentaciones públicas es la faceta que Vallejo presenta, el lector hipotético pregunta a Vallejo ¿eres tú el de los libros?, y su respuesta irónica le concede la razón: "Mis libros no son ficción, son la estricta verdad. Todo lo que aparece en letra de molde es verdad siempre y cuando los procedimientos del escritor no revelen lo contrario, que miente" (Joset, 2006, p. 654); aquí Vallejo no habla de la verdad en su sentido social, como hemos visto, sino de la verdad en el sentido de la construcción estética del escritor, una verdad que se corresponde con la coherencia interna del proyecto creativo, no con su correspondencia con la realidad objetiva.

En este sentido la personificación del personaje solicita un nivel extraliterario de escepticismo por parte del lector. Al llamar la atención sobre el efecto de verdad que produce la declaración del autor en la creencia del lector, Vallejo cuestiona la posibilidad de un pacto autobiográfico sostenido mediante la verdad histórica. En última instancia esta estrategia demuestra que pasar de la creencia en el texto a la creencia en la palabra del autor para validar el texto no es más que otro juego literario; convertir la verdad literaria en la verdad histórica la transforma en una mentira:

Para mí todos los libros son mentira: las biografías, las autobiografías, las novelas, las memorias [...]. Una de nuestras grandes ficciones es llamar a nuestra especie Homo sapiens. No. Se debe llamar Homo alalus mendax, hombre que habla mentiroso. La palabra se inventó para mentir, en ella no cabe la verdad. El hombre es un mentiroso nato y la realidad no se puede apresar con palabras, así como un río no se puede agarrar con las manos. El río fluye y se va, y nosotros con él (Vallejo, 2015, p. 95).

La posición ética de Vallejo es próxima a la filosofía y presupone una antropología negativa que advierte la naturaleza del hombre como maligna (p. 151) en la que el uso de la palabra misma está viciado. Esto elimina la posibilidad del conocimiento por medio del lenguaje y deja al ser humano atrapado entre su subjetividad y su deseo sexual, una existencia sin sentido y sin posibilidad de trascendencia hasta la muerte. Ante esta visión trágica de la existencia, la labor literaria es percibida como una actividad secundaria: "Y las letras, la literatura, ¿ésas qué? También vamos a salir de ellas no bien desaparezca el libro. Lo único verdaderamente importante para el hombre es la alimentación y la cópula" (pp. 55-56); para Vallejo, desde un plano general la literatura es solo un ejercicio estético, no una actividad trascendente; este tipo de afirmaciones, por otro lado, usuales en su discurso crítico, nos brindan indicios para suponer que 
la literatura en Vallejo se encuentra supeditada a un conjunto de coordenadas éticas generales, un hecho que explicaría la razón de su renuencia a elaborar temas propios de la literatura en su discurso crítico y su preferencia por temas de alcance general.

Desde la escritura de Logoi, la literatura para Vallejo (1997) no es entendida desde la originalidad del escritor, sino desde la herencia lingüística; de ahí que la describa "como el reino de lo recibido, como el vasto dominio de la fórmula, del lugar común y del cliché" (p. 29). De esta forma se distancia de la idea romántica del escritor genial, que por medio de su actividad es capaz de transmitir lo absoluto y crear formas originales. Por el contrario, para Vallejo el escritor es valorado por el dominio de las formas literarias establecidas. La literatura no es el vehículo que permite al escritor la experiencia de lo universal o lo verdadero, sino de lo particular; el idioma y su experiencia subjetiva definen su práctica. La literatura produce relatos subjetivos y relativos que, en ningún caso, pueden ser extrapolables por fuera de la semántica literaria.

El rechazo frontal de la tercera persona presente desde El río del tiempo es la evidencia más notable de esta relación de Vallejo con la verdad y la literatura. Desde su posición ética la ficción no puede aspirar a una verdad extraliteraria, o incluso a la producción de una experiencia ajena a la experiencia humana; de ahí que el narrador omnisciente de la tercera persona sea visto como un engaño por imposible. A partir de esto se observa una delimitación precisa de la poética literaria de Vallejo que implica el uso de la primera persona y el trabajo sobre el concepto histórico y literario de verdad. Es interesante que, en lugar de identificar su poética como producto de la posmodernidad, Vallejo la relacione con Cervantes, proponiendo así una identificación simbólica con el centro mismo de nuestro canon:

Antes de Cervantes la novela pretendió siempre que sus ficciones eran verdad y le exigió al lector que las creyera por un acto de fe. Ese fue su gran precepto, la afirmación de su veracidad, así como la tragedia tuvo el suyo, el de la triple unidad de tiempo, espacio y tema. Vino Cervantes e introdujo en el Quijote un nuevo gran principio literario, el principio terrorista del libro que no se toma en serio y cuyo autor honestamente nos dice que lo que nos está contando es invento y no verdad. Lo cual es como negar a Dios en el Vaticano (Vallejo, 2015, p. 94).

La autorreferencialidad presente en las primeras líneas del Quijote le permite a Vallejo leer la novela como un caso de "omnisciencia irónica" (p. 175), donde toda la narración apunta hacia la subjetividad del narrador en quien reside el efecto de verdad y que parodia la novela precedente al señalar su condición ficcional. 
La lectura que Vallejo hace de Cervantes se puede aplicar a su propio proyecto literario, cuyo efecto de verdad se produce por medio de un narrador irónico, el cual aparece de forma constante en sus novelas y alrededor de quien teje un relato autobiográfico. Al hacer de este narrador uno no fiable, Vallejo produce una innovación paródica de la novela autobiográfica, ya que llama la atención del lector sobre la artificialidad que produce su efecto de verdad.

\section{Performatividad}

La innovación de Vallejo no se limita al nivel textual y se extiende al nivel performativo a través de la personificación del personaje. Esta puede definirse como la identificación pública del autor con su personaje a través de la coincidencia entre los registros discursivos atribuidos al personaje en la narración y aquellos expuestos públicamente por el autor por medio de su personificación ante una audiencia. El rasgo característico de la personificación del personaje consiste en que las acciones del escritor por medio de su personificación tienden a producir y afirmar ante el público la ilusión de identidad entre el autor y el personaje elaborado.

Esta es una función literaria extratextual cuya operación es decididamente pública y requiere de la participación activa del escritor, quien busca persuadir a su audiencia de la ilusión de identidad entre personificación y personaje. Puede entenderse como resultado de la interacción cada vez más estrecha entre medios de comunicación y el sistema literario a partir de la segunda mitad del siglo xx, y tiene su paralelo en las distintas esferas creativas, como el cine, la música o las artes visuales, en las que el artista tiene la capacidad performativa de producir y deshacer una persona pública (Andy Warhol o David Bowie, por ejemplo).

La publicación de La virgen de los sicarios (1994), novela paradójicamente aislada de su proyecto autorreferencial, le brinda a Vallejo la exposición pública necesaria para desarrollar su personificación del personaje, sobre todo hacia fines de la década, cuando se produce la polémica alrededor de la representación violenta de Colombia, que se genera a raíz de la adaptación de su novela al cine. A partir de la publicación de El desbarrancadero (2001) se puede hablar de un vínculo claro entre la personificación del personaje y la elaboración narrativa en la que la comunicación es constante entre ambas instancias. 
Vallejo usa en su personificación del personaje los elementos biográficos y ético-críticos de su narrador para producir la ilusión de identidad. Al referirse a su biografía regresa sobre episodios codificados desde El río del tiempo: la infancia en la finca de sus abuelos, la experiencia cinematográfica, sus relaciones familiares o su estancia en México. Y en cuanto a su discurso crítico, en él predominan los temas éticos, políticos y literarios presentes en sus novelas. La transparencia de esta continuidad entre el personaje y su personificación se ve puesta en duda cuando los rasgos no fiables del personaje son transportados a la esfera pública, y puede decir entonces con libertad en un momento que su madre tuvo 22 hijos (Vallejo, 2015, p. 21) y luego cambiar el número por 18 (p. 27), sin que ninguno de los dos se corresponda con la cifra histórica verdadera.

En este mismo sentido, a partir de La rambla paralela (2002), novela en la cual su personaje muere, Vallejo (2015) se declara muerto ante la audiencia: "me morí en mi ley, en primera persona como viví y escribí” (p. 287), y se refiere en adelante a esta condición fantasmal en sus intervenciones públicas señalándola como el final de su proyecto narrativo: "ya maté al loco. Ya está muerto y enterrado. No hay forma de resucitarlo. Lo que yo tenía adentro ya lo saqué para afuera. Ya no hay nada más”(Vallejo, 2017,p.156). A pesar de esto, el personaje de Vallejo reaparece y "vuelve a morir" en su novela El don de la vida (2010), dejando perplejos a quienes confiaban en su "final".

La indeterminación que la personificación del personaje produce en el público resulta de la condición irónica del narrador en la que se sostiene. Si en teoría el efecto de verdad del pacto de lectura autobiográfico se decide de forma extratextual sobre el autor, Vallejo responde con la construcción pública de un autor no fiable y su identificación performativa con el mismo. Señala así, ahora desde un nivel autoral, lo engañoso de los mecanismos de autoridad que producen la creencia literaria. En una entrevista, Ángel Berlanga le pregunta si quien responde las preguntas que le hace es el mismo narrador en primera persona, el personaje de sus novelas que los lectores conocemos, y Vallejo le responde: "Exacto, un personaje. A nadie tenemos por qué decirle nuestra última verdad” (Vallejo, 2004, s.p.). De esta forma las acciones públicas expresadas a través de la personificación del personaje coinciden con la inestabilidad del narrador autobiográfico, quien muere, se desdobla y vuelve a narrar en las novelas de Vallejo bajo proyecciones fantasmales. 
La existencia conjunta de la personificación del autor y la personificación del personaje en Vallejo produce un efecto de ambigüedad sobre la audiencia que está acostumbrada a una relación transparente entre la persona que se presenta en público y la atribución del mensaje que se enuncia. ¿A quién atribuir la responsabilidad de las palabras cuando estas pueden ser interpretadas como expresiones del escritor o como performances? ¿Cómo distinguir entre ambas? El lugar polémico que Vallejo ocupa en la cultura colombiana parte de esta situación de incertidumbre que el propio escritor se ha encargado de exacerbar desde el inicio de su presencia mediática, en la que se lo puede observar tocando música clásica al piano, renegando de la política en Colombia o, travestido con un traje de novia y gafas de sol, exhortando a que los feos y pobres dejen de reproducirse.

$\mathrm{Al}$ asumir la personificación del personaje, Vallejo lleva la irreverencia y la provocación de su literatura hacia la esfera pública, y con ello perturba la representación social del artista intelectual en Colombia. Al producirse este tránsito, el contenido de sus libros pasa a un segundo plano, ya que la discusión no gira de forma primordial en torno a ellos, sino a la personalidad que Vallejo representa en los medios y el lugar social que ocupa como intelectual. En otras palabras, para el gran público ya no importa lo que Vallejo escribe, sino qué simboliza y cómo se desenvuelve en su personificación. Por un lado, se espera que demuestre una personalidad dominante, carismática, capaz de expresarse libremente (Sennett, 1978, p. 238) y que pueda causar conmoción en los demás (p. 250); representaciones sociales construidas alrededor del artista como sujeto público a fines del siglo xix y que le permiten transgredir el orden social: "Sentirse libre para expresarse, desviación, anormalidad: estos tres términos se vuelven absolutamente vinculados una vez que el medio público se transforma en un campo para la revelación de la personalidad" (p. 237). Por otro lado, se espera que al asumir un rol como escritor intelectual mantenga un cierto registro de comportamientos que representen la cultura nacional, que demuestren, por ejemplo, una preocupación genuina por la nación y que formulen su pensamiento como una crítica constructiva que en lo posible sea respetuosa de sus interlocutores y la audiencia.

Esta dicotomía se percibe en Vallejo a través de su personificación ambigua, y presenta una preocupación genuina por la nación alrededor de la cual gira la mayoría de su pensamiento político. No obstante, esta no se adapta a un modelo conciliador, sino que su comportamiento es deliberadamente agonístico, al proponer lecturas y 
soluciones incómodas para el conjunto de la sociedad nacional. Identifica por ejemplo el problema de la violencia y su relación con la política (Vallejo, 2015, p. 227) para luego proponer una solución irónica, la extinción de la especie, puesto que la maldad del hombre es innata: "El hombre nació para el peculado, el soborno, el cohecho, la nómina, el presupuesto, el gobierno, la venalidad, la coima y lo demás son cuentos [...] la tierra es de los granujas"(p. 289). Su discurso elimina la posibilidad de una solución política o religiosa y dirige la atención al sinsentido de la existencia, a la imposibilidad de creer en algo cuando la muerte se presenta como la única certeza: "El Altísimo, con la caridad, es el otro gran invento de los clérigos para estafar a los tontos de aquí abajo. El de los políticos es la patria. La que sí existe es la Nada, de la que nos sacaron unos lujuriosos, hombre y mujer, y a la que volveremos" (Vallejo, 2014, pp. 45-46).

Antes que el rol público del intelectual, Vallejo escoge el modelo del escritor enfrentado a la sociedad que evita la negociación y busca la valoración artística en sus propios términos. Aunque históricamente esta búsqueda parte del debate público sobre el valor de las obras literarias, en su proyecto creativo busca extenderse hacia su pensamiento moral. Es decir, antes que presentar y defender una poética, Vallejo defiende una ética cuyo alcance es extraliterario, de ahí que no aspire al lugar tradicional del escritor moderno sino al del filósofo, el poseedor de "una forma necia de ser" (Vallejo, 2015, p. 56). Detrás de este interés subyace la idea de que la práctica literaria de manera amplia, incluyendo las funciones performativas que Vallejo construye en público, puede ser entendida como una forma de filosofía práctica.

Si bien esta es una concepción heterodoxa e interesante de la práctica literaria, produce un efecto de confusión en la audiencia que puede leer en su personificación ambigua desde la extravagancia artística hasta el material de censura. En todo caso la audiencia necesita de una identidad y personalidad con las cuales asociar el mensaje que recibe. La propuesta filosófica de Vallejo, que llama a la desconfianza de todo aquello más allá de la experiencia subjetiva y que se materializa en la personificación ambigua, no se sostiene como un modo efectivo de comunicación; al minar su autoridad como emisor pone en tela de duda la veracidad y la seriedad de su mensaje ante el público. De forma pragmática prevalece entonces su rol como escritor, y sus actuaciones públicas, que van de la indignación a la diatriba, son percibidas como performances en los que la exageración está ligada a una verdad subjetiva. 


\section{Consideraciones finales}

La personificación ambigua que opera en el proyecto literario de Fernando Vallejo no tiene referentes en nuestra región, ya que se aleja tanto del uso del álter ego construido a partir de una base autobiográfica (cuyo estatus semificcional es reconocido en público por el escritor), como de la identificación pública entre personaje y autor (que podría derivar en una autobiografía o en una autoficción). Vallejo acepta y niega al mismo tiempo una identificación con el personaje no fiable que aparece en su proyecto autorreferencial y lo lleva a un nivel extratextual, al personificarlo de forma consciente ante el público. Esta es una comprensión amplia de la literatura, que nos indica cómo el escritor es cada vez más consciente de las formas en las que puede operar en el espacio público para jugar con la recepción de su figura y sus textos.

La literatura latinoamericana, en especial a partir del último cuarto del siglo $\mathrm{xx}$, además de un giro autobiográfico presenta uno performativo; las consecuencias de este fenómeno son un campo abierto de estudios que llaman a la reflexividad disciplinar sobre el objeto y el alcance de los estudios literarios. Al igual que en las artes visuales, en las que el paradigma retiniano fue cuestionado por la irrupción del arte conceptual, el camino parece abierto para pensar la literatura como un conjunto de operaciones que giran en torno la producción social de lo literario y cuyo estudio no puede ignorar el papel que juegan en ello las relaciones creativas que se producen entre el público y el autor.

\section{Referencias bibliográficas}

Barolsky, P. (2010). A Brief History of the Artist from God to Picasso. University Park: The Pennsylvania State University Press.

Bourdieu, P. (1995). Las reglas del arte: génesis y estructura del campo literario. Barcelona: Anagrama.

Goffman, E. (2001). La presentación de la persona en la vida cotidiana. Buenos Aires: Amorrortu.

Habermas, J. (1997). Historia y crítica de la opinión pública: la transformación estructural de la vida pública. Barcelona: Ediciones G. Gili.

Joset, J. (2006). Entrevista a Fernando Vallejo. Iberoamericana 215-216, pp. 653- 655.

Lejeune, P. (1994). El pacto autobiográfico y otros estudios. Madrid: Megazul-Endymion.

Musitano, J. (2017). Fernando Vallejo biógrafo. La vida de los otros y la potencia de la autofiguración. Literatura y Lingüistica 36, pp. 139-148. DOI: http://dx.doi.org/10.4067/S0716-58112017000200139 Sennett, R. (1978). El declive del hombre público. Barcelona: Ediciones Península. 
Soussloff, C. (1997). The Absolute Artist: The Historiography of a Concept. Minneapolis: The University of Minnesota Press.

Vallejo, F. (1984). Barba Jacob, el mensajero. Ciudad de México: Séptimo Círculo.

Vallejo, F. (1997). Logoi: una gramática del lenguaje literario. Ciudad de México: Fondo de Cultura Económica.

Vallejo, F. (1999). El río del tiempo. Bogotá: Alfaguara.

Vallejo, F. (2004). ¡Qué horror si Colombia se menemiza! Página 12. Recuperado de https://www.pagina12.com.ar/diario/cultura/7-38734-2004-07-25.html [28.06.2020]

Vallejo, F. (2014). El cuervo blanco. Bogotá: Alfaguara.

Vallejo, F. (2015). Peroratas. Bogotá: Alfaguara.

Vallejo, F. (2017). Para mí la literatura es un borrador de recuerdos. En H. Salswach (ed.). 70 años de conversaciones con escritores de paso (pp. 155-157). Caracas: Fondo Editorial Banesco.

Villena Garrido, F. (2005). 'La sinceridad puede ser demoledora'. Conversaciones con Fernando Vallejo. Ciberletras 12. Recuperado de http://www.lehman.cuny.edu/ciberletras/v13/villenagarrido.htm [28.06.2020] 